\title{
The evolutionist's tale
}

\section{A journey back through our evolution with a growing band of ancestors.}

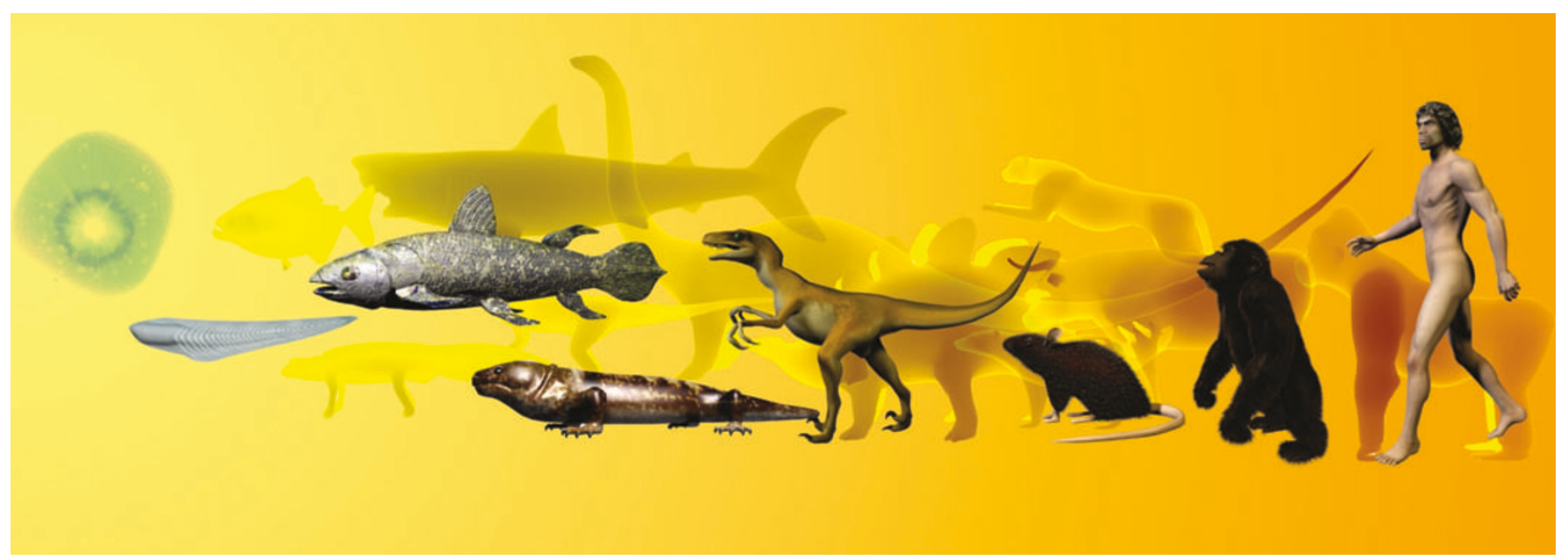

The Ancestor's Tale: A Pilgrimage to the Dawn of Life

by Richard Dawkins

Weidenfeld \& Nicholson (UK)/Houghton Mifflin (US): 2004.528 pp. $£ 25 / \$ 28$

\section{Jerry A. Coyne}

Richard Dawkins' success as a popularizer of science lies in his remarkable ability to convey complex, subtle and technical issues without dumbing them down or patronizing the reader. It also helps that he writes beautifully and, as is evident from the titles of his books (think of The Selfish Gene or The Blind Watchmaker), has an exceptional gift for using metaphor to capture and solidify abstract ideas. Until now, Dawkins has dealt with concepts - most notably natural selection - for it is in the explication of ideas that he excels. In The Ancestor's Tale, however, he leaves his familiar literary niche. Instead of ideas, he traffics here in facts: the history of life on Earth. Facts, however, don't need metaphors. How does Dawkins handle this new direction in his work?

Perhaps conscious that his arrival in 'fact-land' must differ from that of previous travellers (two other Richards - Fortey and Southwood - have recently published splendid overviews of life's history for the general reader), Dawkins uses a pair of gimmicks to enliven his parade of information.

First, he writes his history in reverse. Beginning with modern humans and moving backwards in time, he describes our lineage as we successively join - a geneticist would say coalesce - with the common ancestors of other species. Human evolution has involved 40 such joints, each occupied by what Dawkins calls a "concestor", and each is the subject of a single chapter. $\mathrm{He}$ begins, of course, with our common ancestor with chimps, followed by the concestor with gorillas, then other primates, and so on through the fusion with early mammals, sponges, plants, Eubacteria and ultimately the Ur-species, probably a naked molecule of RNA. This narrative is engagingly written and attractively illustrated with reconstructions of the concestors, colourful phylogenies, and photographs of bizarre living species. The book is also remarkably up to date and, despite its size, nearly error-free. Especially notable are Dawkins' treatments of human evolution and the origin of life, the best accounts of these topics I've seen in a crowded literature.

Second, lacking more familiar metaphors, Dawkins adopts a literary conceit, modelling the book on Geoffrey Chaucer's The Canterbury Tales. This parallel itself takes two forms. Dawkins views species as pilgrims marching into the past, joining each other genetically on a 3-billion-year journey to evolution's Canterbury: the first "replicator". In addition, he fleshes out his phylogeny with 58 sidebars: chaucerian "pilgrim's tales" told by extant species, each describing a biological concept or method.

How well does this literary parallel work? The answer is mixed. The reverse-history tactic is useful, emphasizing as it does our common ancestry with other groups, but it is somewhat anthropocentric, following only one thread - ours - in the tapestry of life. The pilgrims' tales, on the other hand, represent a return to terra firma for Dawkins, as they deal largely with ideas. These stories are clearly the centrepiece of the book, not only for the reader, but seemingly for Dawkins himself. (One can almost sense his relief as he interrupts his dutiful account of amphibian evolution to explain the evolutionary significance of "ring species" in salamanders and seagulls.)

Although Dawkins aficionados will rec- ognize some tales from his earlier books, most are new and absorbing. The grasshopper's tale, for example, uses geographic variation within orthopteran species to inspire a remarkably sensible treatment of human racial variation, a topic whose political overtones usually drive biologists to panicked circumlocution. The peacock introduces us to sexual selection, the flounder to evolutionary imperfection, and the rotifer to the disadvantage of reproducing sexually. A lot of arcane but engrossing biology lies buried in these tales: we learn, for example, why some electric fish swim without undulation (such movement would distort the electric fields that aid navigation and prey detection), and why anteaters are the only animals that do not digest their food with hydrochloric acid (formic acid from ants does the job nicely).

Occasionally, however, the combination of history and pilgrims' tales fails to cohere, and both elements sometimes have a whiff of the textbook. Several digressions, such as the exhaustive explanations of $\log -\log$ plots, radiometric dating and molecular clocks, are simply too long and complicated. These stories are familiar to scientific readers, but are likely to fatigue rather than inspire the laity. It is not that this material is dull - Dawkins could make a field guide lively reading — but that it sometimes lacks the intellectual spark that fired his previous works.

In view of the book's breadth and the author's strong opinions on many issues, any biologist can find something to criticize. My main gripe is Dawkins's strong emphasis apparently influenced by the work of Geoffrey Miller - on sexual selection as a likely engine for the evolution of important human traits, including a large brain and bipedal gait. Dawkins suggests, for instance, that ancestral females favoured males who were smarter and adopted an attractive 
vertical posture. But unless such traits improve the fitness of both males and females (in which case natural selection alone can do the job), sexual selection will produce differences between the sexes, as it probably did with human body size. Why, then, don't we see knuckle-walking women with chimpanzee-sized brains? Although we may never know why humans became erect and brainy, sexual selection seems among the least plausible of many alternative theories.

Despite its considerable merits, The Ancestor's Tale seems the least compelling of
Dawkins' works. Given the author's talents, however, this may be akin to judging Coriolanus Shakespeare's least compelling play. Thankfully, Dawkins returns to top form in the final chapter, a philosophical overview of the extraordinary events he's just recounted. Here he grapples with questions of whether evolution would produce similar creatures if it began anew (a qualified yes), and whether evolution itself promotes "evolvability", making species even more likely to respond to future selection (another qualified yes).

His final sentences are quintessential
Dawkins, with language at its most lambent and elegant, used simply to express profound truths: "The fact that life evolved out of nearly nothing ... is a fact so staggering that I would be mad to attempt words to do it justice. And even that is not the end of the matter. Not only did evolution happen: it eventually led to beings capable of comprehending the process, and even of comprehending the process by which they comprehend it."

Jerry A. Coyne is in the Department of Ecology and Evolution, University of Chicago, Chicago, Illinois 60637, USA.

\section{First steps in science}

\section{Curious Minds: How a Child \\ Becomes a Scientist \\ edited by John Brockman \\ Pantheon: 2004. 256 pp. \$23.95, £16.99 \\ Paul L. Harris}

John Brockman asked 27 distinguished scientists from diverse fields, including physics, psychology, biology, mathematics and robotics, to write a short biographical sketch, describing their childhood and what got them hooked on science. The heterogeneity of the essays they wrote serves as an antidote to easy speculation about there being any essential precursors to scientific accomplishment.

Is a scientifically oriented family important? It looks that way at first as you read through the opening piece by psychologist Nick Humphrey. One of his early memories - vividly described - is of being taken by his grandfather on Boxing Day to dissect a frog in the empty, silent anatomy department of University College, London. The grandfather, as it happens, has a Nobel prize in physiology, and is just one family figure in a distinguished panoply. Humphrey candidly writes: "What I gained from this childhood environment was a sense of intellectual entitlement — a right to ask questions, to pry, to provoke, to go where I pleased in pursuit of knowledge."

That sense of intellectual entitlement is echoed by cognitive scientist Alison Gopnik. She writes of her parents' devotion to their children's intellectual lives, not with a view to "enrichment" or "achievement", but with a gift for making such intellectual activity "the accepted, ordinary, happy way that civilized people went about their lives". Ray Kurzweil, an inventor, recalls a similarly intense intellectual life in his family circle: "The intense and animated discussions were invariably about new ideas, usually those of intellectuals I had never heard of. The way for me to get attention was to have an idea."

But consider, by contrast, the childhood

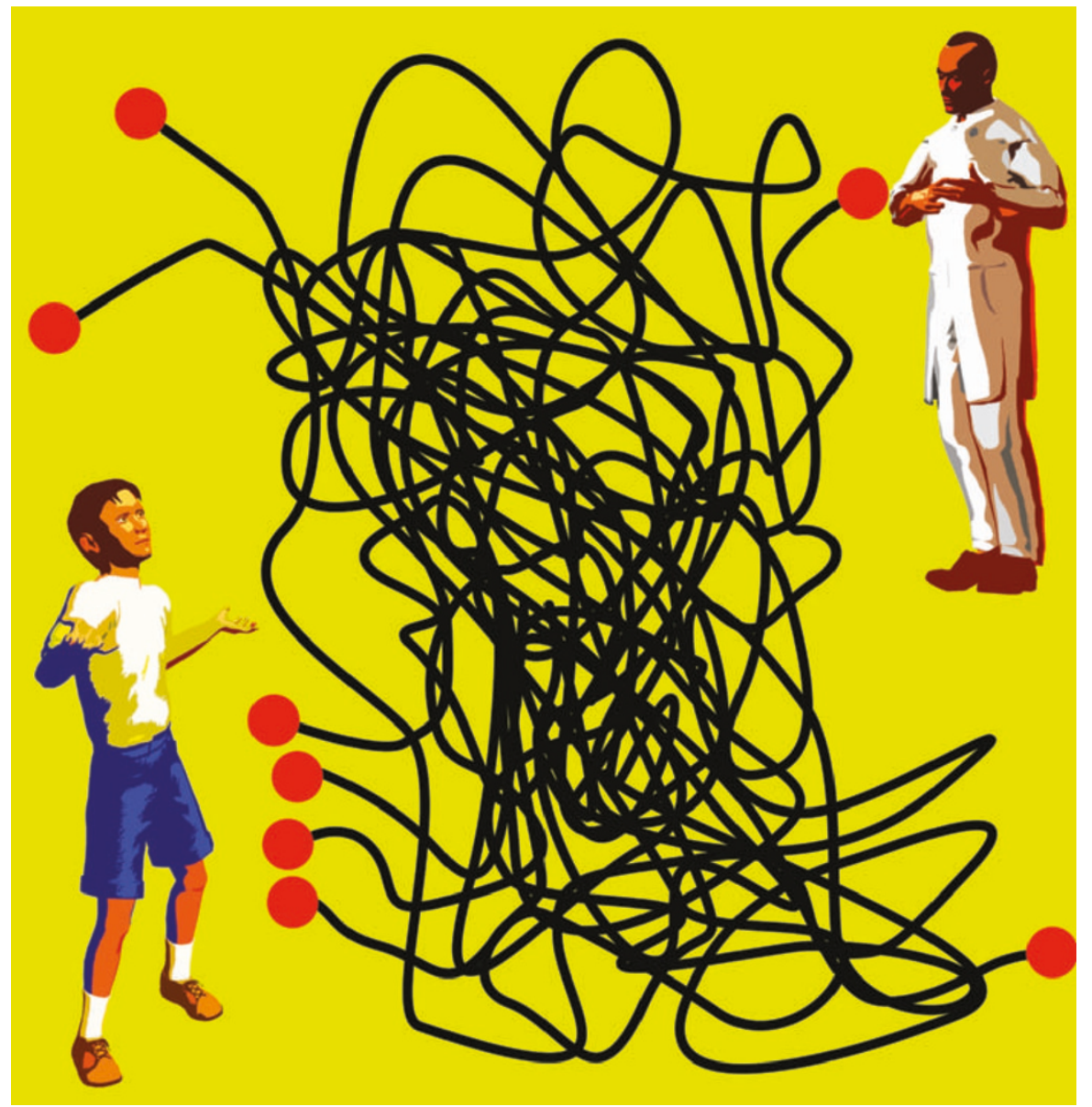

of the computer scientist Jaron Lanier. His mother died when he was nine and he was raised by an indigent father with an interest in psychic phenomena. For a while they lived in tents in southern New Mexico before moving into a fragile geodesic dome designed by his father. Such an eccentric upbringing might nurture intellectual independence, but it's a long way from the scientific dynasty described by Humphrey or the high-minded but nurturing family in which Gopnik was raised. Neuroscientist Joseph LeDoux describes an equally unpropitious start. His father was a bull rider in the rodeo and hoped that his only child would emulatehim.

Another plausible candidate for later scientific accomplishment is a keen childhood interest in some branch of the natural world: insects, stars, fossils or electricity. Some contributors do display such a passion. Computer scientist Rodney Brooks, for example, was already fascinated by electric circuits at the age of seven. And Lynn Margulis, a biologist, writes of lying on her belly to watch ant colonies. Yet there are disconcerting exceptions. Another biologist, Richard Dawkins, tells an amusing story about mistaking a blue tit for a chaffinch. Shocked at the boy's error, his grandfather turned to Dawkins' father and remonstrated: "Good God, John —is that possible?"

The conclusion that does emerge from this collection is that a huge number of different paths lead to a successful scientific career. Some can be tentatively traced back 